\title{
Activity of omeprazole on Helicobacter pylori and relation to toxicity of strains
}

\author{
N Figura, D Armellini, M Bugnoli, P F Bayeli, C Gennari, J E Crabtree
}

\begin{abstract}
Aims-To see whether the activity of omeprazole on Helicobacter pylori is associated with toxicity of strains; to determine whether omeprazole inhibited vacuolisation of cells in culture induced by $H$ pylori cytotoxin and by ureas, and if omeprazole prevented $H$ pylori motility.

Methods-Minimal inhibitory concentrations (MICs) of omeprazole were determined for seven cytotoxic and five non-cytotoxic $H$ pylori strains. Omeprazole at different concentrations was incubated with cytotoxic and noncytotoxic extracts of $\boldsymbol{H}$ pylori, or with purified $H$ pylori urease, and added to cells in culture. Inhibition of motility by omeprazole was tested in semi-solid medium.
\end{abstract}

Results-MIC M $_{90}$ of omeprazole was 40 $\mu \mathrm{g} / \mathrm{ml}$. MICs for cytotoxic and noncytotoxic organisms were similar. Omeprazole did not prevent vacuolisation induced by the cytotoxic extract, but at high concentrations it inhibited the formation of vacuoles induced by urease. Motility was not inhibited by the drug.

Conclusions-H pylori cytotoxin is not omeprazole. Should the drug reach clinically effective concentrations in vivo, it could potentially prevent the mucosal damage caused by the vacuolising activity of urease.

(F Clin Pathol 1994;47:440-442)

Istituto di Patologia Speciale Medica, University of Siena, Policlinico Le Scotte, V le Bracci, I-53100 Siena, Italy

N Figura

P F Bayeli

C Gennari

IRIS, Via Fiorentina 1, Siena

D Armellini

M Bugnoli

Department of

Medicine, St James's

University Hospital,

Leeds

J E Crabtree

Correspondence to:

Dr Natale Figura

Accepted for publication 25 November 1993

Omeprazole is a gastric parietal cell proton pump inhibitor that is also active against Helicobacter pylori in vitro. ${ }^{1}$ Proton pumps are adenosinetriphosphatases (ATPases) which regulate the transport of ions inside the cells. A recent study has reported that internal sequences of certain ATPases are similar to the amino terminal sequence of the vacuolising toxin-a protein of about 87 kilodaltons in its denatured form-produced by cytotoxic $H$ pylori strains. ${ }^{2}$ Because of this similarity, vacuolising toxin could, in theory, interfere with proton pump ATPases which regulate the flux of ions at the level of the gastric cell endocytic compartment and so induce vacuole formation. ${ }^{2}$

If the latter hypothesis is true omeprazole may possibly inhibit vacuolisation induced by cytotoxic $H$ pylori strains by blocking the stimthe target of the antimicrobial activity of

ulation of bacterial ATPase. Vacuolising toxin could also be the target, or one of the targets, which account for the antimicrobial activity of omeprazole. Both the antibacterial effect and the inhibition of vacuolisation could explain the improvement of gastric lesions observed after treatment with omeprazole. ${ }^{3}$ If omeprazole can influence bacterial ATPases it could have other effects on $H$ pylori activities that require energy consumption-for instance, it could inhibit bacterial motility.

Thus the purpose of this study was first to examine whether the susceptibility of $H$ pylor strains to omeprazole depended on cytotoxin production, and if omeprazole could inhibit the vacuolisation induced in vitro by extracts of cytotoxic $H$ pylori, and whether it could also inhibit $H$ pylori motility. Secondly, we investigated whether omeprazole inhibits the vacuolisation exerted by $H$ pylori urease on cells in culture: Bugnoli et $a l,{ }^{4}$ using a spectrophotometric technique, showed that omeprazole inhibits purified $H$ pylori urease activity. ${ }^{4}$ Urease can also induce vacuolisation of cells in vitro in the presence of urea. ${ }^{5}$ If omeprazole inhibits $H$ pylori urease activity in vivo too, it could prevent the gastric epithelium from being injured by the ammonia produced subsequent to urea hydrolysis.

\section{Methods}

Twelve $H$ pylori strains were tested for susceptibility to omeprazole. Seven strains were cytotoxic (including the type strain CCUG 17874); five strains were non-cytotoxic. Strains were stored at $-80^{\circ} \mathrm{C}$ in WilkinsChalgren broth (Oxoid) with $20 \%$ glycerol.

Omeprazole was dissolved in methanol and included in Columbia agar with $10 \%$ horse blood at concentrations ranging from $5 \mu \mathrm{g} / \mathrm{ml}$ to $160 \mu \mathrm{g} / \mathrm{ml}$. Bacteria from 48 hour plate cultures were suspended in Brucella broth at $2-4 \times 10^{8}$ organisms $/ \mathrm{ml}$. Five microlitres of each suspension were dropped on to agar, and plates were incubated in a microaerobic environment at $37^{\circ} \mathrm{C}$ for five days. The minimal inhibitory concentration (MIC) was regarded as the lowest concentration of omeprazole at which no bacterial growth was visible.

To investigate whether omeprazole inhibited vacuole formation caused by the toxin in vitro, a water extract and an ultrasonicate of the cytotoxic $H$ pylori CCUG 17874 were mixed with omeprazole $(6 \cdot 2 \mu \mathrm{g}-100 \mu \mathrm{g} / \mathrm{ml})$ and added to HeLa cells in culture. HeLa cells were cultured in Dulbecco modified Eagle's medium (DMEM) with 5\% fetal 
bovine serum in a $5 \%$ carbon dioxide atmosphere at $37^{\circ} \mathrm{C}$. Cells were detached by trypsin, suspended in DMEM, seeded in 96 well plates at a density of $3 \times 10^{3}$ cells per well, and allowed to adhere for 24 hours. Bacterial extracts were used at twice the vacuolising titre (the highest dilution of bacterial extracts at which $50 \%$ or more cells were vacuolated after 18 hours of incubation). Samples were added in triplicate to semiconfluent HeLa cells and incubated for 18 hours. Vacuolisation inhibition was verified microscopically and by the neutral red method. ${ }^{56}$ Briefly, cells were stained with $0.1 \mathrm{ml}$ per well of $0.05 \%$ neutral red in phosphate buffered saline (PBS) (pH 7.4) at $25^{\circ} \mathrm{C}$ for four minutes. After washing three times with $0.2 \mathrm{ml}$ of $0.2 \%$ bovine serum albumin in PBS the dye was eluted with acid alcohol $(70 \%$ ethanol in water containing $0.37 \% \mathrm{HCl}$ ). Vacuolised cells concentrate neutral red; acid alcohol dissolves the dye. The intensity of the colour was measured spectrophotometrically $(530 \mathrm{~nm})$, and the result expressed as optical density (OD) $\times 1000$.

A water extract of non-cytotoxic $H$ pylori G21, omeprazole alone, methanol alone, and uninoculated cells were used as controls.

\section{UREASE VACUOLISATION INHIBITION TEST}

Examination of the effect of omeprazole on vacuolisation induced by urease was carried out with the enzyme purified chromatographically from $H$ pylori CCUG 17874 according to the method of $\mathrm{Hu}$ and Mobley. ${ }^{7}$ The activity of the enzyme was assayed both spectrophotometrically, as discussed before, ${ }^{4}$ and by testing vacuolising activity on HeLa cells in culture in the presence of $10 \mathrm{mM}$ urea. The test for vacuole inhibition was performed in triplicate in microtitre plates with $1 \mu \mathrm{g} / \mathrm{ml}$ of urease $(0 \cdot 125-4 \mu \mathrm{g} / \mathrm{ml}$ urease induced the same degree of vacuolisation) and $6 \cdot 2 \mu \mathrm{g}-100$ $\mu \mathrm{g}$ omeprazole/ml. Cultures which had not been supplemented with urea were used as controls.

\section{MOTILITY INHIBITION TEST}

There is no codified test to assay $H$ pylori motility. Owen et al used the hanging drop method. ${ }^{8}$ We subsequently found that the motility test in soft agar $(0.27 \%$ to $0.35 \%)$ gave more clearcut results. Therefore, the motility inhibition test was carried out in semi-solid medium which consisted of Brucella broth (Difco) with $0.35 \%$ noble agar (Difco), 1\% Vitox supplement (Oxoid), 10\% inactivated fetal bovine serum, and omeprazole at concentrations ranging from $5 \mu \mathrm{g}$ to 80 $\mu \mathrm{g} / \mathrm{ml}$. Four fully motile $H$ pylori strains from 48 hour cultures were tested. A loopful of bacteria was stabbed by about $2 \mathrm{~mm}$ under the surface of the agar and streaked for about 4 $\mathrm{cm}$. Plates were incubated right side up in a microaerobic environment at $37^{\circ} \mathrm{C}$ for five days. As a control, semi-solid agar without omeprazole (in which motile strains difuse for about $5 \mathrm{~mm}$ at both sides of the streak) was used.

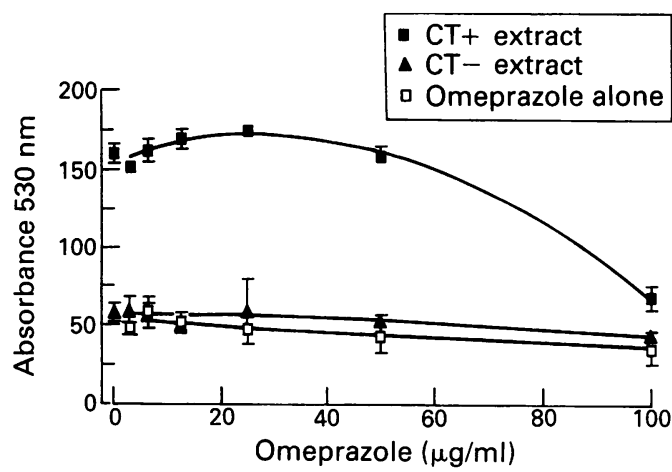

Figure 1 The effects of omeprazole on neutral red uptake by HeLa cells induced by water extracts of cytotoxin positive (CT+) H pylori strain CCUG 17874 and cytotoxin negative strain G21. Values are mean (SEM) $O D$.

\section{Results}

All strains were inhibited at $40 \mu \mathrm{g}$ omeprazole per $\mathrm{ml}$. The MIC of omeprazole for five cytotoxic and three non-cytotoxic strains was 20 $\mu \mathrm{g} / \mathrm{ml}$. Therefore, no difference in susceptibility was found whether or not the strains produced cytotoxin.

The effects of omeprazole on in vitro cytotoxicity of the water extract of $H$ pylori CCUG 17874 is shown in fig 1 . Omeprazole at concentrations of 3.1 to $50 \mu \mathrm{g} / \mathrm{ml}$ had no effect on cytotoxicity. Omeprazole at $100 \mu \mathrm{g} / \mathrm{ml}$ seemingly prevented vacuolisation induced by the cytotoxic extracts. However, at that concentration, while no vacuoles were visible, the cells looked rounded and swollen. Similar results were obtained with the ultrasonicated bacterial preparation. The OD obtained with a water extract of the non-cytotoxic strain and with omeprazole alone were similar (fig 1). The mean (SEM) OD with methanol alone, corresponding to the methanol concentration in the well with $100 \mu \mathrm{g}$ omeprazole per $\mathrm{ml}$, was 47 (7); with uninoculated cells, OD was 63 (3). The effect of omeprazole on vacuolisation induced by $H$ pylori urease in the presence of $10 \mathrm{mM}$ urea is shown in fig 2 . Omeprazole, at 100 and $50 \mu \mathrm{g} / \mathrm{ml}$, prevented vacuolisation induced by urease. ODs of the control samples without the urea supplement were similar at the different concentrations of omeprazole.

$H$ pylori motility was not inhibited at omeprazole concentrations lower than those which inhibited the growth of bacteria.

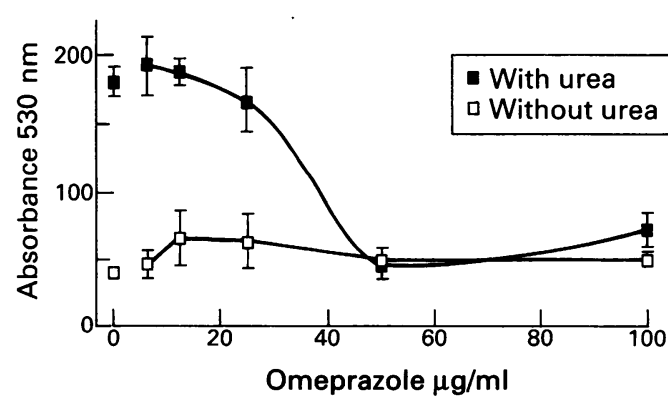

Figure 2 The effects of omeprazole on neutral red uptake by HeLa cells induced by purified $H$ pylori urease in the presence of $10 \mathrm{mM}$ urea. Values are mean (SEM) OD. 


\section{Discussion}

It is not clear which mechanism(s) account(s) for the antimicrobial activity of omeprazole. When used in dual or triple treatment, omeprazole increases eradication of $H$ pylori. ${ }^{9}$ Several studies have demonstrated the selective bacteriostatic effect of benzimidazole proton pump inhibitors on $H$ pylori in vitro, ${ }^{1}$ but the strains used have not been characterised for cytotoxin production. In this study we have shown that the susceptibility of $H$ pylori to omeprazole does not depend on the cytotoxicity of strains. The cytotoxin is not, therefore, the target of the antibacterial activity of the drug. Additionally, subinhibitory concentrations of omeprazole had no effect on bacterial motility.

Omeprazole had no inhibitory effects on in vitro vacuolisation induced by cytotoxic $H$ pylori extracts except at the highest concentration of $100 \mu \mathrm{g} / \mathrm{ml}$. The vacuole inhibition observed at this concentration is probably due to a toxic effect of the drug on the cells. Vacuolisation is an active phenomenon and does not take place if the cells are not fully vital (N Figura, personal observation). Vacuole formation has recently been shown to depend on the cellular induction of a vacuolar-type ATPase. ${ }^{6}$ The inability of omeprazole to inhibit vacuolisation induced by cytotoxic $H$ pylori extracts suggests that omeprazole is not active against vacuolar-type ATPases. Vacuolisation induced by the urease enzyme in the presence of $10 \mathrm{mM}$ urea, however, was inhibited by omeprazole at the lower concentration of $50 \mu \mathrm{g} / \mathrm{ml}$. Bugnoli et al $^{4}$ have recently shown that omeprazole will competi- tively inhibit urease activity. If omeprazole reaches urease inhibitory concentrations in vivo, it could therefore potentially prevent the mucosal damage caused by the vacuolising activity of urease.

The selective action of benzimidazole proton pump inhibitors against $H$ pylori led Iwahi et $a l^{l}$ to suggest that the target could be a biochemical pathway unique to the organism. As the susceptibility to omeprazole does not depend on the presence of urease ${ }^{4}$ or the cytotoxin as shown in this study, then other bacterial components must be the target.

1 Iwahi $T$, Satoh H, Nakoa $M$, et al. Lansoprazole, a novel benzimidazole proton pump inhibitor, and its related compound have a selective activity against Helicobacter compound have a selective activity against Helico

2 Cylon. Antimicrob Agents Chemother 1991;35:490-6. the vacuolating toxin from Helicobacter pylori. $\mathcal{F}$ Biol Chem 1992;267:10570-5.

3 Daw MA, Deegan P, Leen E, O'Morain C. The effect of omeprazole on Helicobacter pylori and associated gastritis. Aliment Pharmacol Ther 1991;5:435-9.

4 Bugnoli M, Bayeli PF, Rappuoli R, Pennatini C, Figura N, Crabtree JE. Inhibition of Helicobacter pylori urease by omeprazole. Eur $\mathcal{F}$ Gastroenterol Hepatol 1993;5:683-5.

5 Cover TL, Puryear W, Perez-Perez GI, Blaser MJ. Effect of urease on HeLa cell vacuolation induced by of urease on HeLa cell vacuolation induced by
Helicobacter pylori cytotoxin. Infect Immun 1991;59: 1264-70.

6 Papini E, Bugnoli M, De Bernard M, Figura N, Rappuoli $\mathrm{R}$, Montecucco C. Bafilomycin Al inhibits Helicobacter pylori induced vacuolization of HeLa cells. Mol Microbiol 1993;7:323-7.

$7 \mathrm{Hu}$ LT, Mobley LT. Purification and N-terminal analysis of urease from Helicobacter pylori. Infect Immun 1990;58. 992-8.

8 Owen RJ, Figura N, Moreno M. Biotypes and DNA fingerprints of cytotoxigenic Helicobacter pylori from patients with gastritis and peptic ulceration in Italy. Eur $\mathcal{F}$ Epidemiol 1992;8:15-21.

9 Bell GD, Powell K, Weil J, et al. Experience with omeprazole in combination with either amoxycillin or colloidal bismuth subcitrate in patients with metronidazolebismuth subcitrate in patients with metronidazole-
resistant Helicobacter pylori. Eur $f$ Gastroenterol Hepatol 1991;3:923-6. 